\title{
Production of a biocrust-cyanobacteria strain (Nostoc commune) for large-scale restoration of dryland soils
}

\author{
B. Roncero-Ramos ${ }^{1}$ (1) • J. R. Román ${ }^{1}$ • C. Gómez-Serrano ${ }^{2}$ • Y. Cantón ${ }^{1,3}$ • F. G. Acién ${ }^{2}$
}

Received: 24 May 2018 / Revised and accepted: 28 January 2019

(C) Springer Nature B.V. 2019

\begin{abstract}
Cyanobacteria colonize the soil surface in deserts where they coexist with other organisms such as mosses, lichens, bacteria, fungi, archaea, and microalgae, in communities known as biocrusts. Cyanobacteria are of interest for dryland restoration due to their capacity for survival under water stress, facilitating succession and influencing soil function recovery. In addition, their large-scale culturing in bioreactors is possible. The aims of this study were to optimize the biomass production of a soil cyanobacterium (Nostoc commune) and determine the feasibility of employing fertilizers instead of chemicals for their production. The suitability of the biomass produced in different culture media for inducing biocrusts was tested by inoculation on sterilized mine substrate and then measuring several soil properties. Results showed that the growth rate of biomass cultured in the fertilizer media $\left(0.43\right.$ day $\left.^{-1}\right)$ was close to the chemical media. After 3 months of incubation in soil the cyanobacteria surface coverage increased up to $36 \%$ and there was no difference between soils inoculated with biomass produced in chemical or fertilizer media. As the Mann and Myers medium made with fertilizers promoted the best soil improvements, such as increased soil organic carbon and exopolysaccharide content of $8.9 \mathrm{~g} \mathrm{~kg}^{-1}$ and $2.2 \mathrm{mg} \mathrm{g}^{-1}$, respectively, a growth model was calculated to optimize its production in this medium for future large-scale restoration. Our results demonstrate that Nostoc commune can be economically produced for improving degraded soils, reducing the cost of the medium by $295 € \mathrm{ha}^{-1}$.
\end{abstract}

Keywords Biological soil crust $\cdot$ Soil cyanobacteria $\cdot$ Low-cost cyanobacteria production $\cdot$ Growth model $\cdot$ Restoration

\section{Introduction}

Plant interspaces in drylands are frequently colonized by cyanobacteria and organisms such as lichens, mosses, microalgae, fungi, archaea, or heterotrophic bacteria, which live together in close association with soil particles (Belnap et al. 2016) forming biological soil crusts (BSCs) or biocrusts. Biocrusts benefit soil fertility (Chamizo et al. 2012), protect it from water and wind erosion (Rodríguez-Caballero et al. 2012), and increase water availability at the soil surface (Chamizo et al. 2016), providing important ecosystem services in drylands (Rodríguez-Caballero et al. 2017). Their

\section{B. Roncero-Ramos}

brr275@ual.es

1 Agronomy Department, University of Almería, Almería, Spain

2 Department of Chemical Engineering, University of Almería, Almería, Spain

3 Centro de Investigación de Colecciones Científicas de la Universidad de Almería (CECOUAL), University of Almeria, Almería, Spain recovery should be therefore considered crucial to restoring ecosystem functioning, and in designing approaches to dryland restoration (Bowker 2007). Cyanobacteria are the first biocrust colonizers of dryland soils (Weber et al. 2016) and the most resistant, as well as the easiest to culture under laboratory conditions, making them key organisms to inducing biocrust development on degraded soils (Wang et al. 2009). For biocrust induction, first a native cyanobacterium strain is selected, the biomass is produced and then inoculated on the soils to be restored (Rossi et al. 2017). Several studies have achieved good results with lab-scale inoculation of cyanobacteria on soil in Petri dishes (Chamizo et al. 2018; Muñoz-Rojas et al. 2018; Román et al. 2018; Mugnai et al. 2018a, b). Although there have been some field inoculation studies (Chen et al. 2006; Wang et al. 2009; Rao et al. 2012; Lan et al. 2013; Wu et al. 2013a, b; Park et al. 2017), there are still many problems for its large-scale application to restoration of degraded areas, such as the need for large amounts of biomass, which may represent a significant production cost.

Nostoc commune is of interest for inoculation trials because of its suitable ecological and physiological characteristics (Zhao et al. 2016; Rossi et al. 2017). It is usually found in 
biocrusts inhabiting cosmopolitan dryland environments (Lange and Belnap 2016), including Mediterranean dryland ecosystems (Cano-Díaz et al. 2018; Roncero-Ramos et al. 2019). Nostoc spp. are heterocystous cyanobacteria which have dryland survival strategies, such as pigment (chlorophyll $a$, scytonemin, and carotenoids) production, $\mathrm{CO}_{2}$ fixation by photosynthesis (Whitton and Potts 2012), atmospheric nitrogen $\left(\mathrm{N}_{2}\right)$ fixation by heterocysts, and exopolysaccharide (EPS) generation (Schopf 2013). The matrix of EPS, water, lipids, proteins, and other compounds surrounding cyanobacterial trichomes promotes soil colonization by reducing moisture loss under dry environmental conditions (Rossi and De Philippis 2015), enhancing soil particle aggregation, and preventing erosion (De Philippis and Vincenzini 1998). It also protects cyanobacteria against predation and antibacterial agents (De Philippis and Vincenzini 1998). Scytonemin in the matrix protects cells from UV radiation (Garcia-Pichel and Castenholz 1991). Furthermore, most soil cyanobacterial metabolisms are adapted to hydration-dehydration cycles (Dodds et al. 1995), remaining inactive during dry periods and becoming active again with water availability. Terrestrial Nostoc spp. have also shown tolerance to UV-B during desiccationrehydration (Gao and Ye 2007) and are an early successional soil colonizer, following bundle-forming cyanobacteria (Belnap and Eldridge 2003). These strategies benefit BSCs by improving soil functions, such as increasing soil fertility by fixing atmospheric $\mathrm{C}$ and N (Belnap 2003); increasing soil stability, through EPS production, and water availability (Chamizo et al. 2012, 2016); and decreasing soil albedo (Román et al. 2018). Several studies have proven the potential of Nostoc spp. for inoculation in soil restoration, such as in the one by Román et al. (2018), which showed the successful induction of an incipient biocrust after inoculating $N$. commune on different types of soil, leading to an increase in organic carbon and total nitrogen soil content. Furthermore, McKenna Neuman et al. (1996) reported that the crust produced after nurturing $N$. commune inoculants on sand under greenhouse conditions provided considerable protection against wind erosion. Other species belonging to the Nostoc genus have also been inoculated on soils under laboratory conditions with good results, e.g., improving soil porosity (Falchini et al. 1996) or aggregate stability (Rogers and Burns 1994). These studies suggest that inoculation of $N$. commune on dryland soils under natural conditions would be an effective restoration method. However, for the restoration of large degraded areas, its production would have to be optimized.

Scaling up cyanobacteria biomass production to inoculate large degraded areas is one of the most complicated steps in optimization. In recent decades, the cost of biomass production has been lowered by optimizing growing temperatures, making use of sunlight (Rossi et al. 2017), and using wastewater instead of a freshwater enrichment medium (Wu et al.
2018). Nevertheless, the process is still expensive (Hu et al. 2012), and further optimization is necessary if this technology is to be used to restore large areas. Usually, chemical media are employed (e.g., BG11 (Rippka et al. 1979) or AN (Allen and Arnon 1955)). One of the most influential factors in biomass production cost is the medium (Acien et al. 2012), so a reduction in its cost would be reflected in the total balance. One strategy for this is the use of agricultural fertilizers, which have already been used with excellent results for production of microalgae and water cyanobacteria (Guzmán-Murillo et al. 2007; Nayak et al. 2016). However, they have never been used with soil cyanobacteria.

This study analyzed the feasibility of producing the soil cyanobacterial strain, $N$. commune, in fertilizer media as a low-cost strategy. The biomass produced was then inoculated on a degraded soil to accelerate the development of BSCs, in comparison with natural biocrust recovery rates. After 3 months of nurturing, several soil properties were analyzed to demonstrate the suitability of the inoculants for dryland soil restoration projects. This article evaluates the best production strategy based on culture results and their effects on degraded soil properties.

\section{Materials and methods}

\section{Microorganism and culture conditions}

The cyanobacterial strain employed was morphologically and genetically identified as Nostoc commune CANT2 UAM 817 (Roncero-Ramos et al. 2019), order Nostocales. It was isolated from biocrusts in a limestone quarry in the foothills of the Sierra de Gádor Mountains at $370 \mathrm{~m}$ a.s.l. $\left(36^{\circ} 55^{\prime} 20^{\prime \prime} \mathrm{N}, 2^{\circ}\right.$ $30^{\prime} 29^{\prime \prime} \mathrm{W}$ ), in a semiarid region of SE Spain (Luna et al. 2016), and maintained in autoclaved BG11 $1_{0}$ (Rippka et al. 1979) and Arnon+N (Allen and Arnon 1955) liquid media at $25^{\circ} \mathrm{C}$ and $70 \mu \mathrm{mol}$ photons $\mathrm{m}^{-2} \mathrm{~s}^{-1}$.

A two-factor design was used to test the effect of adding a nitrogen source to culture media and preparing them with fertilizers instead of chemicals. Nostoc commune was therefore cultured in four different media (Table 1), two of which were prepared using pure chemicals, the traditional BG11 (Rippka et al. 1979) with and without nitrogen, because $N$. commune is a nitrogen-fixing cyanobacterium. The third medium (BG11-F) was made to simulate the composition of BG11 but prepared using agricultural fertilizers. As compounds (fertilizers and chemicals, see Table 1) were different, the composition of the BG11 medium made with fertilizers was adjusted to make the quantities of the main elements as similar as possible. After adjustment, differences in $\mathrm{P}$ and $\mathrm{Ca}$ in media were less than $0.01 \mathrm{~g} \mathrm{~L}^{-1}$ and for $\mathrm{Na}$ and $\mathrm{N}$ less than $0.03 \mathrm{~g} \mathrm{~L}^{-1}$. The fourth (MM-F) was the Mann and Myers medium (Mann and Myers 1968) commonly employed for 
Table 1 Composition of culture media used

\begin{tabular}{|c|c|c|c|c|c|}
\hline Fertilizers $\left(\mathrm{g} \mathrm{L}^{-1}\right)$ & BG11-F & MM-F & Pure compounds ( $\left.\mathrm{g} \mathrm{L}^{-1}\right)$ & BG11 $1_{0}$ & BG11 \\
\hline $\mathrm{Ca}\left(\mathrm{NO}_{3}\right)_{2}$ & 0.0125 & 0.640 & $\mathrm{CaCl}_{2} \cdot 2 \mathrm{H}_{2} \mathrm{O}$ & 0.0360 & 0.0360 \\
\hline $\mathrm{NaNO}_{3}$ & 0.3500 & 0.260 & $\mathrm{NaNO}_{3}$ & 0.0000 & 0.5000 \\
\hline $\mathrm{MgSO}_{4}$ & 0.0370 & 0.180 & $\mathrm{MgSO}_{4} \cdot 7 \mathrm{H}_{2} \mathrm{O}$ & 0.0750 & 0.0750 \\
\hline $\mathrm{KH}_{2} \mathrm{PO}_{4}$ & 0.0290 & 0.140 & $\mathrm{~K}_{2} \mathrm{HPO}_{4} \cdot 3 \mathrm{H}_{2} \mathrm{O}$ & 0.0400 & 0.0400 \\
\hline Welgro* & 0.045 & 0.045 & $\mathrm{Na}_{2} \mathrm{MgEDTA}$ & 0.0002 & 0.0002 \\
\hline \multirow[t]{9}{*}{$\mathrm{Fe}$} & 0.0110 & 0.011 & $\mathrm{C}_{6} \mathrm{H}_{11} \mathrm{FeNO}_{7}$ & 0.0060 & 0.0060 \\
\hline & & & $\mathrm{C}_{6} \mathrm{H}_{8} \mathrm{O}_{7}$ & 0.0066 & 0.0066 \\
\hline & & & $\mathrm{Na}_{2} \mathrm{CO}_{3}$ & 0.0200 & 0.0200 \\
\hline & & & $\mathrm{H}_{3} \mathrm{BO}_{3}$ & 0.0286 & 0.0286 \\
\hline & & & $\mathrm{MnCl}_{2} \cdot 4 \mathrm{H}_{2} \mathrm{O}$ & 0.0181 & 0.0181 \\
\hline & & & $\mathrm{ZnSO}_{4} \cdot 7 \mathrm{H}_{2} \mathrm{O}$ & 0.0022 & 0.0022 \\
\hline & & & $\mathrm{Na}_{2} \mathrm{MoO}_{4} \cdot 2 \mathrm{H}_{2} \mathrm{O}$ & 0.0039 & 0.0039 \\
\hline & & & $\mathrm{CuSO}_{4} \cdot 5 \mathrm{H}_{2} \mathrm{O}$ & 0.0008 & 0.0008 \\
\hline & & & $\mathrm{Co}\left(\mathrm{NO}_{3}\right)_{2} \cdot 6 \mathrm{H}_{2} \mathrm{O}$ & 0.0005 & 0.0005 \\
\hline
\end{tabular}

*The units of Welgro are $\mathrm{mL} \mathrm{L}^{-1}$

All fertilizers, except for Welgro, were at 95\% of purity (Yara, Spain). Welgro is a solution of micronutrients (B, $\mathrm{Mn}, \mathrm{Zn}, \mathrm{Mo}, \mathrm{Fe}, \mathrm{Cu}$ ) (Yara, Spain) large-scale production of microalgae, prepared using fertilizers (Sánchez Mirón et al. 1999; Fernandez et al. 2012; Barceló-Villalobos et al. 2018). The molarities of $\mathrm{N}$ and $\mathrm{P}$ and the N/P ratio in the media were BG11 $(\mathrm{N}=0.006 \mathrm{M}$, $\mathrm{P}=0.0004 \mathrm{M}, \mathrm{N} / \mathrm{P}=15), \mathrm{BG} 11_{0}(\mathrm{~N}=0 \mathrm{M}, \mathrm{P}=0.0002 \mathrm{M}$, $\mathrm{N} / \mathrm{P}=0)$, BG11-F $(\mathrm{N}=0.004 \mathrm{M}, \mathrm{P}=0.0002 \mathrm{M}, \mathrm{N} / \mathrm{P}=9)$, and MM-F $(\mathrm{N}=0.011 \mathrm{M}, \mathrm{P}=0.001 \mathrm{M}, \mathrm{N} / \mathrm{P}=5)$. Finally, the production costs of each culture medium, calculated by taking into account the prices and quantities of each one of the chemicals and fertilizers employed to prepare them, were $0.003 € \mathrm{~L}^{-1}$ (MM-F and BG11-F), $0.018 € \mathrm{~L}^{-1}\left(\mathrm{BG} 11_{0}\right)$, and $0.03 € \mathrm{~L}^{-1}$ (BG11).

\section{Photobioreactor and operating conditions}

Twelve bubble column reactors with a hemispherical base and a total volume of $0.3 \mathrm{~L}(3 \mathrm{~cm} \times 45 \mathrm{~cm})$ were used for the cyanobacterial production experiments. They were placed in a temperature-controlled chamber at $25^{\circ} \mathrm{C}$. Eight $28 \mathrm{~W}$ fluorescent tubes (Philips Daylight T5) were installed horizontally to provide a solar 12:12 $\mathrm{h}$ daylight cycle with a maximum irradiance of $1600 \mu \mathrm{mol}$ photons $\mathrm{m}^{-2} \mathrm{~s}^{-1}$. The solar cycle was simulated by turning on a pair of fluorescent tubes every $1.5 \mathrm{~h}$ to increase irradiance, starting out at $290 \mu \mathrm{mol}$ photons $\mathrm{m}^{-2} \mathrm{~s}^{-1}$, followed by 800 and $1400 \mu \mathrm{mol}$ photons $\mathrm{m}^{-2} \mathrm{~s}^{-1}$, until reaching the maximum which lasted $3 \mathrm{~h}$, and then decreasing following the same pattern. The reactors were continuously aerated with air sterilized by filtering $(0.22 \mu \mathrm{m}$, Millex EMD Millipore) at $0.1 v / v / \mathrm{min}$ (air flow volume per volume of liquid per minute) to remove oxygen and ensure adequate mixing.
The $\mathrm{pH}$ of all culture media was set at 7.8 the first day of the essay.

The reactors were operated in batch mode. Each reactor was filled with a culture prepared by mixing each medium with $10 \%$ of a previously adapted inoculum, as the strain must always be adapted to the medium before batch culturing, especially in nitrogen-free media. For this, $N$. commune was cultured in $0.5 \mathrm{~L}$ of nitrogen-free medium until it developed nitrogen-fixing heterocysts. Three replicates were evaluated for each medium defined.

\section{Culture monitoring}

During batch culturing, each reactor was manually shaken daily and opened in a sterile atmosphere. Any water that evaporated was replaced with autoclaved distilled water and then $10 \mathrm{~mL}$ of the culture was extracted. Dry weight, $F_{\mathrm{v}} / F_{\mathrm{m}}$, and the visible absorption range were measured in each daily extraction. Dry weight was used to determine the biomass concentration $\left(C_{\mathrm{b}}\right)$ by filtering $(1 \mu \mathrm{m}$ pore size, $9 \mathrm{~cm}$ diameter, Whatman) the extract and keeping the filtered biomass in an oven at $80{ }^{\circ} \mathrm{C}$ for $24 \mathrm{~h}$. The $F_{\mathrm{v}} / F_{\mathrm{m}}$ ratio was defined as the estimated maximum quantum yield of $Q_{\mathrm{A}}$ reduction, that is, the maximum photochemical efficiency of photosystem II (PSII) (Cosgrove and Borowitzka 2010), measured with a Junior-PAM fluorimeter (Walz, Germany) after culture adaptation in the dark for $15 \mathrm{~min}$. Chlorophyll absorption $(680 \mathrm{~nm}$ and $750 \mathrm{~nm})$ and the complete visible absorption range $(400-700 \mathrm{~nm})$ in the extracts were measured with a 
fluorimeter (Aquapen AP C100, PSI, Czech Republic). The biomass extinction coefficient $\left(K_{\mathrm{a}}\right)$, which represents the biomass light absorption efficiency (Grima et al. 1994), was obtained at the start of the experiment to determine the irradiance attenuation in the culture. It was calculated by applying the Beer-Lambert law (Beer 1852 ) as the ratio between the average absorbance in the visible spectrum and the biomass concentration $\left(C_{\mathrm{b}}\right)$ in the light path through the cuvette $(p=0.01 \mathrm{~m})$ (Eq. 1).

$\mathrm{K}_{\mathrm{a}}=\overline{\operatorname{Abs}}_{(\lambda=400-700 \mathrm{~nm})} /\left(\mathrm{C}_{\mathrm{b}} * p\right)$

The average cell exposure to irradiance inside the culture $\left(I_{\text {av }}\right)$ was calculated following Molina Grima et al. (1993) (Eq. 2 ), as a function of the irradiance in the absence of biomass $\left(I_{0}\right)$, the extinction coefficient of the biomass $\left(K_{\mathrm{a}}\right)$, the biomass concentration $\left(C_{\mathrm{b}}\right)$, and the light path through the cuvette $(p)$.

$\mathrm{I}_{\mathrm{av}}=\frac{\mathrm{I}_{0}}{\mathrm{~K}_{\mathrm{a}} * C_{\mathrm{b}} * p} *\left(1-e^{\left(-\mathrm{K}_{\mathrm{a}}{ }^{*} \mathrm{C}_{\mathrm{b}} * p\right)}\right)$

The specific growth rate $(\mu)$, defined as the capacity of biomass generation per biomass unit, was determined as the slope of $\operatorname{Ln}\left(C_{\mathrm{b}} / C_{0}\right)$ over time $(t)$ (Eq. 3), where $C_{0}$ is the initial biomass concentration of the culture (Gomez-Serrano et al. 2015; Morales-Amaral et al. 2015). This parameter is of interest if the culture has growth limitations, such as irradiance. To determine the quantity of biomass generated per volume of culture over time, the volumetric biomass productivity $\left(P_{\mathrm{b}}\right)$ was calculated as the product of the specific growth rate $(\mu)$ and the biomass concentration $\left(C_{\mathrm{b}}\right)(\mathrm{Eq} .4)$ (Gomez-Serrano et al. 2015; Morales-Amaral et al. 2015). Calculations were performed daily.

$\mu=\frac{\operatorname{Ln}\left(\mathrm{C}_{\mathrm{b}} / \mathrm{C}_{0}\right)}{t}$

$P_{b}=\mu^{*} C_{b}$

The parameters $\left(I_{\mathrm{av}}, k_{\mathrm{a}}\right.$, and $\left.\mu\right)$ calculated above were fitted to the growth model in (Eq. 5) (Molina Grima et al. 1993) to find the maximum specific growth rate $\left(\mu_{\max }\right)$, irradiance constant $\left(I_{\mathrm{k}}\right)$, and the form parameter $(n)$. This model has been shown to be useful for representing the growth of microalgae and cyanobacteria in different production systems. It is mainly a function of the average irradiance, which also integrates the geometry of the system, the biomass concentration, and the cell absorption properties. As a sigmoidal effect has been observed at low light intensities and with nutrient limitations, the $n$ parameter was included to adjust the growth kinetics for it (Molina Grima et al. 1993). According to this model, the growth rate of any microalgal strain is a hyperbolic function of the average irradiance inside the culture, which is determined by external irradiance, the light path length, the biomass extinction coefficient, and the biomass concentration inside the culture (Eq. 5).

$\mu=\frac{\mu_{\mathrm{max}} I_{\mathrm{av}}^{\mathrm{n}}}{I_{\mathrm{k}}^{\mathrm{n}}+I_{\mathrm{av}}^{\mathrm{n}}}$

\section{EPS determination in liquid culture}

The EPS in the liquid culture was determined to find out whether differences in media would affect the $N$. commune production of EPS, and whether the quantity of EPS in the inoculant would influence cyanobacterial colonization of soil. The Ahmed et al. (2014) method was slightly modified to extract the total EPS of $0.1 \mathrm{~L}$ of liquid culture from each reactor. Extractions were divided into two categories, the EPS released in the media by cyanobacteria (labeled, released EPS (REPS)) and the EPS associated with cells by covalent bonds (CEPS). The REPS fraction was obtained after centrifuging culture samples $\left(5000 \times \mathrm{g}, 20 \mathrm{~min}, 20^{\circ} \mathrm{C}\right)$ and filtering the supernatant with $0.45 \mu \mathrm{m}$ filters (Millipore) to eliminate cyanobacteria cells. The CEPS extraction was done in two steps. First, the pellet was mixed with $4.5 \mathrm{~mL}$ of milli-Q water and incubated for $1 \mathrm{~h}$ at $30^{\circ} \mathrm{C}$ while shaking at $120 \mathrm{rpm}$. Afterwards, it was centrifuged and filtered under the same conditions as before, keeping the fraction obtained. The rest of the CEPS were extracted by adding $4.5 \mathrm{~mL}$ of $0.1 \mathrm{M}$ $\mathrm{Na}_{2}$ EDTA to the remaining pellet and incubating it for $4 \mathrm{~h}$ at $25{ }^{\circ} \mathrm{C}$ while shaking at $120 \mathrm{rpm}$. Finally, it was centrifuged and filtered as before and mixed with the previous fraction extracted with milli-Q water to obtain the whole CEPS fraction. All the extractions were determined by the phenolsulfuric acid method (Dubois et al. 1956), measuring absorbance $(488 \mathrm{~nm})$ with a spectrophotometer (Helios Zeta UVVIS, Thermo, UK). Then, both fractions were combined to obtain the total EPS in each culture.

\section{Cyanobacteria inoculation on soil}

Petri dishes (diameter $=90 \mathrm{~mm}$, depth $=15 \mathrm{~mm})$ were filled with $80 \mathrm{~g}$ of $2 \mathrm{~mm}$-sieved substrate from the limestone quarry, which had previously been sterilized by autoclaving twice for $20 \mathrm{~min}$ at $120^{\circ} \mathrm{C}$, to avoid any interaction with the indigenous soil community. Then, they were watered from above to promote the development of a physical soil crust on the surface, to mimic the natural succession from physical crusts to incipient cyanobacterial biocrusts.

When the batch culture reached the stationary phase, the contents of the three replicates of each culture medium were mixed to produce homogenous soil inoculants for each inoculation treatment. There were seven treatments, which were 
applied on the soil surface in four replicates, for a total of 28 Petri dishes. Four treatments were made up of the $N$. commune biomass and their corresponding media: $\mathrm{BG} 11_{0}$, BG11, MMF, BG11-F. Two more treatments from the culture grown in BG11-F were added to test the influence of the fertilizers on soil: Medium (BG11-F batch culture medium without biomass) and Cyanobacteria (the cyanobacteria biomass cultured in BG11-F without the medium). The Medium treatment consisted of $0.015 \mathrm{~L}$ of medium from the BG11-F batch culture, which had previously been filtered to eliminate cyanobacteria. The Control treatment consisted of watering the Petri dishes with $0.015 \mathrm{~L}$ of distilled water, with no inoculum. Previous studies had tested the cyanobacteria biomass concentration to be inoculated in this soil (Román et al. 2018) and found the $6 \mathrm{~g}$ of dry biomass per $\mathrm{m}$ surface proposed by Maqubela et al. (2010) to be suitable. To reach that concentration per soil surface, all inoculants containing biomass were dilluted with distilled water to a biomass concentration of $2.66 \mathrm{~g} \mathrm{~L}^{-1}$ (except for the Cyanobacteria inoculum which was filtered and resuspended in distilled water) and $0.015 \mathrm{~L}$ of each was inoculated with a sterile pipette on soil in Petri dishes, distributing it as uniformly as possible over the entire surface of each Petri dish.

After inoculation, all Petri dishes were incubated in a Fitotron Plant Growth Chamber (Air-Frio, Almería, Spain) at $25 \pm 1{ }^{\circ} \mathrm{C}$, under watering and $60 \mu \mathrm{mol}$ photons $\mathrm{m}^{-2} \mathrm{~s}^{-1}$ irradiance in a 16-h photoperiod for 90 days. To avoid disturbing the soil/biocrust surfaces, the Petri dishes were perforated on the bottom (very fine pores) before filling and placed in aluminum plates which were filled with $20 \mathrm{~mL}$ per day (the amount necessary for this soil sample to reach field capacity) of distilled water two consecutive days a week to promote cyanobacterial growth in a hydration-desiccation cycle. Irrigation was calculated based on the mean annual rainfall at the experimental site during a wet year in the region (290 mm) (Luna et al. 2016).

\section{Evaluation of induced biocrust characteristics}

At the end of the experiment, zenithal images were taken with a CANON EOS 600D digital camera from a distance of $25 \mathrm{~cm}$ above the sample. Cyanobacteria cover was estimated by applying a supervised maximum likelihood classification to the images. Two cover classes were defined, bare soil and biocrust. Each image was first processed by identifying 600 training points and applying a supervised maximum likelihood classification with ENVI 4.3 (ITT VIS, USA). Chlorophyll $a$ analyses were performed by the doubleextraction method (Castle et al. 2011), measuring the absorbance at $665 \mathrm{~nm}$ with a spectrophotometer (Helios Zeta UVVIS, Thermo, UK). Surface reflectance response was measured on all samples with an ASD FieldSpec Hand Held portable spectroradiometer (ASD Inc., USA) with a $3.5-\mathrm{nm}$ optical resolution from 325 to $1075 \mathrm{~nm}$ under constant light conditions. The optical fiber was hung $16 \mathrm{~cm}$ from the Petri dish surface to capture the reflectance of the entire surface of the dish. Before each measurement, a white reference was recorded using a Spectralon panel to find the reflectance factor. Spectral extremes were eliminated to avoid noisy bands, leaving a spectrum from 400 to $950 \mathrm{~nm}$. Then, a smoothing procedure based on a cubic polynomial filter with a 17-band window size was applied (Savitzky and Golay 1964). Afterwards, the spectral absorption of chlorophyll $a$ $(680 \mathrm{~nm})$ and the carotenoids $(490 \mathrm{~nm})$ were calculated employing the continuum removal technique (Clark and Roush 1984), and the albedo was determined as the mean of all bands within the visible spectrum: $R_{(400-700)}$ (RodríguezCaballero et al. 2015).

\section{Changes in soil chemical properties promoted by inoculants}

At the end of the trial, after measuring cover and spectrum, the surface crust (0-3 mm deep) was scraped, dried, and ground in a mortar. Soil organic carbon content (SOC) was determined by the Walkley and Black method modified by Mingorance et al. (2007), by measuring the absorbance $(590 \mathrm{~nm}$ ) of the oxidized organic matter in a spectrophotometer (Helios Gamma, Thermo, England). $0.1 \mathrm{~g}$ of soil was taken for EPS extraction differentiated into loosely bound EPS (LB-EPS) and tightly bound EPS (TB-EPS), following the method of Chen et al. (2014) and Rossi et al. (2018). First, $5 \mathrm{~mL}$ of distilled water was added to the soil, vortexed and left incubating for $15 \mathrm{~min}$ at $20^{\circ} \mathrm{C}$. Afterwards, it was centrifuged $\left(4000 \times g, 20 \mathrm{~min}, 9^{\circ} \mathrm{C}\right)$ and the supernatant was extracted and classified as the LB-EPS fraction. Then, $3 \mathrm{~mL}$ of $0.1 \mathrm{M}$ $\mathrm{Na}_{2}$ EDTA was added to the remaining pellet, mixed by vortexing and incubating for $15 \mathrm{~min}$ at $20^{\circ} \mathrm{C}$. After centrifuging as described above, the supernatant was extracted and stored. Finally, this process was repeated three times and all supernatants were mixed together and classified as the TBEPS fraction. The same method as described in EPS determination in liquid culture was employed for determining both fractions.

\section{Statistical analyses}

The Anova function (package car) was used to perform the ANOVA analyses followed by the Tukey post hoc test to analyze between-treatment differences in soil parameters and the EPS content in the culture media. Data had previously been analyzed for normal distribution with the Shapiro-Wilk test and normalized with the Box-Cox equation (Box and Cox 1964) (boxcox function in the MASS package). Analyses were performed with R 3.4.2 (Development Core Team 2017). 


\section{Results}

\section{Biomass production}

After 17 days of batch culture, the largest biomass concentration was found in the BG11 chemical medium with nitrogen (BG11) (5.0 $\mathrm{g} \mathrm{L}^{-1}$ ) (Fig. 1a), and the lower of $2.4 \mathrm{~g} \mathrm{~L}^{-1}$, in the BG11 medium, also using chemicals (BG11 $1_{0}$ ), but with no nitrogen source. With fertilizers instead of chemicals, the biomass concentration at the end of batch culture was up to $4.0 \mathrm{~g} \mathrm{~L}^{-1}$ in BG11-F, and therefore similar to culturing N. commune in BG11 made with chemicals, and $3.1 \mathrm{~g} \mathrm{~L}^{-1}$ the Mann and Myers medium, with nitrogen and fertilizers (MM-F), which was only slightly higher than without nitrogen $\left(\mathrm{BG} 11_{0}\right)$. Chlorophyll fluorescence measurements $\left(F_{\mathrm{v}} / F_{\mathrm{m}}\right)$ presented common values that ranged from 0.35 to 0.45 in all cases.

In all the culture media, the maximum growth rate was observed at the beginning of the batch culture when the biomass concentration was lowest and light availability highest (Fig. 1b). As expected, the growth rate decreased over time in all the culture media down to close to zero in the stationary

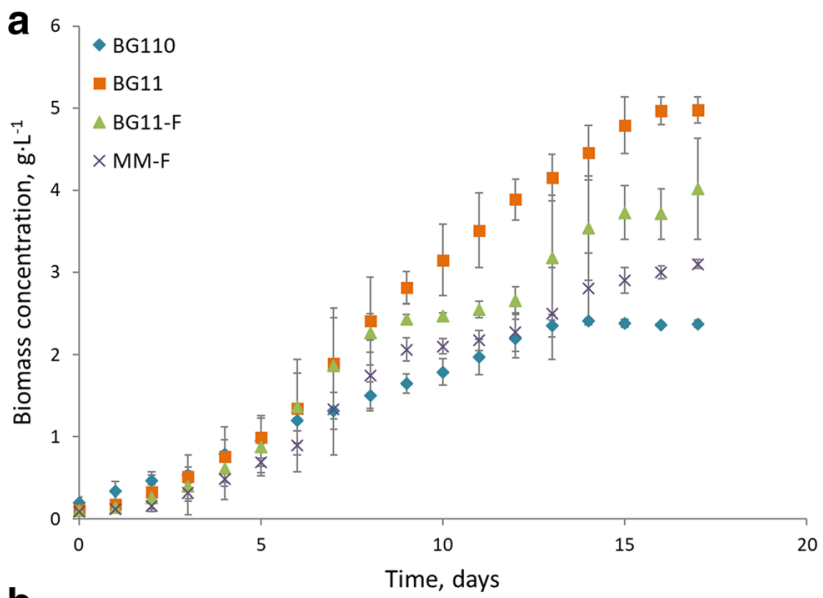

b

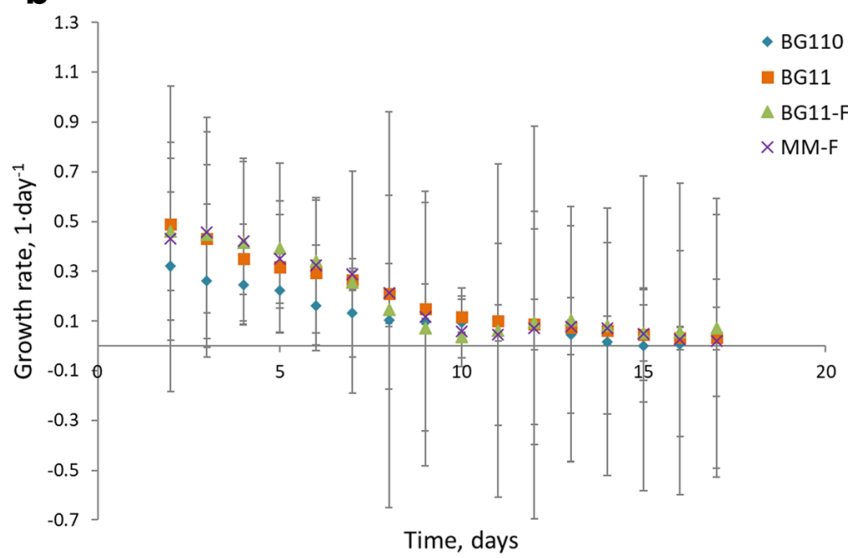

Fig. 1 Influence of culture medium composition on the biomass concentration (a), growth rate (b), biomass productivity (c), and exopolysaccharide concentration (d) of $N$. commune batch cultures in bubble column photobioreactors under artificial light simulating phase at the end of the batch culture. During batch culturing, the growth rate was clearly lower when the culture medium had no nitrogen, whereas differences in the other culture media tested were not large, with maximum growth rates ranging from 0.43 to 0.50 day $^{-1}$.

Both BG11 media (BG11 and BG11-F) with a nitrogen source made with either chemicals or fertilizers showed a maximum biomass productivity of up to $0.5 \mathrm{~g} \mathrm{~L}^{-1}$ day ${ }^{-1}$ on day 7 (Fig. 1c), when the biomass concentration and growth rate were from 1.9 to $2.0 \mathrm{~g} \mathrm{~L}^{-1}$ (Fig. 1a) and from 0.26 to 0.29 day $^{-1}$ (Fig. 1b), respectively. The maximum biomass productivity for the Mann and Myers medium was $0.38 \mathrm{~g} \mathrm{~L}^{-1}$ day $^{-1}$, followed by the BG11 medium with no nitrogen source which was $0.18 \mathrm{~g} \mathrm{~L}^{-1}$ day $^{-1}$.

\section{EPS production in liquid culture}

After analyzing the total amount of EPS produced by cyanobacteria in liquid culture (Fig. 1d), the lowest concentration was found in nitrogen-free chemical BG11 (1.26 $\left.\mathrm{g} \mathrm{L}^{-1}\right)$. The highest total EPS concentration of

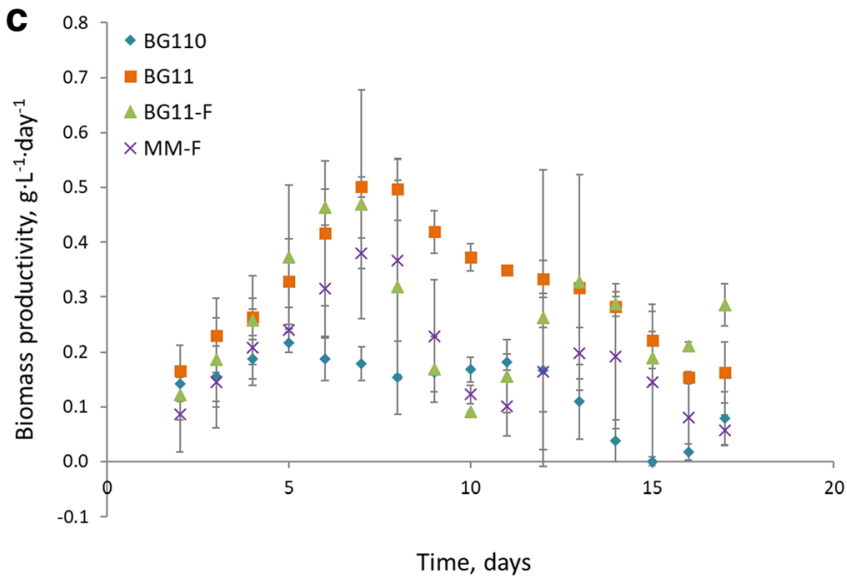

d

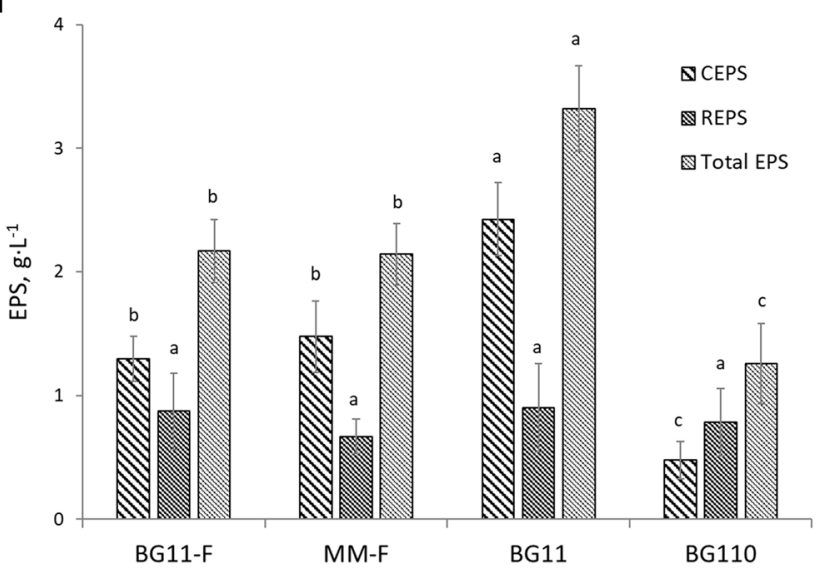

outdoor conditions. All data are means $(n=3)$. The error bars represent $\pm \mathrm{SE}$ and letters indicate significant differences $(p<0.05)$ among each EPS fraction in all treatments 
$3.3 \mathrm{~g} \mathrm{~L}^{-1}$ was found in the BG11 medium containing a nitrogen source and chemicals instead of fertilizers. The total amounts obtained when culturing the cyanobacteria in both media made with fertilizers were very similar ranging from 2.2 to $2.4 \mathrm{~g} \mathrm{~L}^{-1}$. The amounts of EPS released in the media (REPS) were not significantly different; therefore, the significant differences found in the total EPS were due to the covalent EPS (CEPS), which followed the same trend (Fig. 1d).

\section{Induced biocrust characteristics}

After 3 months of cyanobacterial incubation in soils, surface albedo showed the most significant decreases in soils inoculated with $N$. commune cultured in the MM-F, BG11-F, and BG11 0 media, ranging from 17.6 to $19.3 \%$ (Fig. 2), closely followed by Cyanobacteria inoculants and BG11 (22.5-22.6\%). The albedo found in the Control (30\%) and Medium (27.5\%) inoculants was significantly higher (Fig. 2).

Cyanobacteria coverage significantly increased after 3 months of nurturing in all soils inoculated with biomass 21 to $35 \%$ more than the Control and Medium inoculants (Figs. 2 and 3). Chlorophyll $a$ content was also significantly higher in soils inoculated with cyanobacteria biomass than content with the Medium or Control treatments, which was close to zero (Fig. 2). The significant maximum ( $\left.4.3 \mu \mathrm{g} \mathrm{g}^{-1}\right)$ chlorophyll content was reached with the MM-F medium. Nostoc commune growth in $\mathrm{BG} 11_{0}, \mathrm{BG} 11-\mathrm{F}$, and the BG11 media led to lower chlorophyll $a$ content of 1.8, 1.5 and $1.1 \mathrm{\mu g} \mathrm{g}^{-1}$, respectively. Cyanobacteria inoculation with distilled water (Cyanobacteria) led to a very low content of $0.3 \mu \mathrm{g} \mathrm{g}^{-1}$ (Fig. 2).

The continuum removal technique applied to the reflectance spectrum of inoculated soils showed two characteristic absorption peaks for all soils inoculated with cyanobacteria biomass, one related to carotenoid at $490 \mathrm{~nm}$, and the other for chlorophyll $a$ at $680 \mathrm{~nm}$ (Fig. 4). The soils inoculated with MM-F inoculum had the lowest (i.e., deepest) peak absorption for both chlorophyll $a(0.66)$ and carotenoids (0.78), as well as soils inoculated with BG11 $1_{0}$ and BG11-F inoculants (chlorophyll $a 0.73$ and carotenoid 0.81). Significantly higher absorption peaks were observed for soils inoculated with BG11 (chlorophyll $a$ absorption 0.76, carotenoid absorption 0.85) and Cyanobacteria inoculants (chlorophyll $a$ absorption 0.85 , carotenoid absorption 0.85 ).

\section{Changes in soil chemical properties}

Three months after quarry soil inoculation, SOC was significantly higher in all soils inoculated with $N$. commune biomass than control soils inoculated with distilled water or the Medium. Of the inoculants containing cyanobacteria biomass, the significantly highest increases in SOC were found for cyanobacteria cultured in MM-F $\left(9.86 \mathrm{~g} \mathrm{~kg}^{-1}\right)$, BG11, and BG11 0 media (in a range of 6.8 to $6 \mathrm{~g} \mathrm{~kg}^{-1}$ ) (Fig. 5).

Three months after inoculation, both EPS fractions (TB-EPS and LB-EPS) showed the same significantly higher trend in all soils treated with inoculants containing biomass with media than in the Control, Medium,

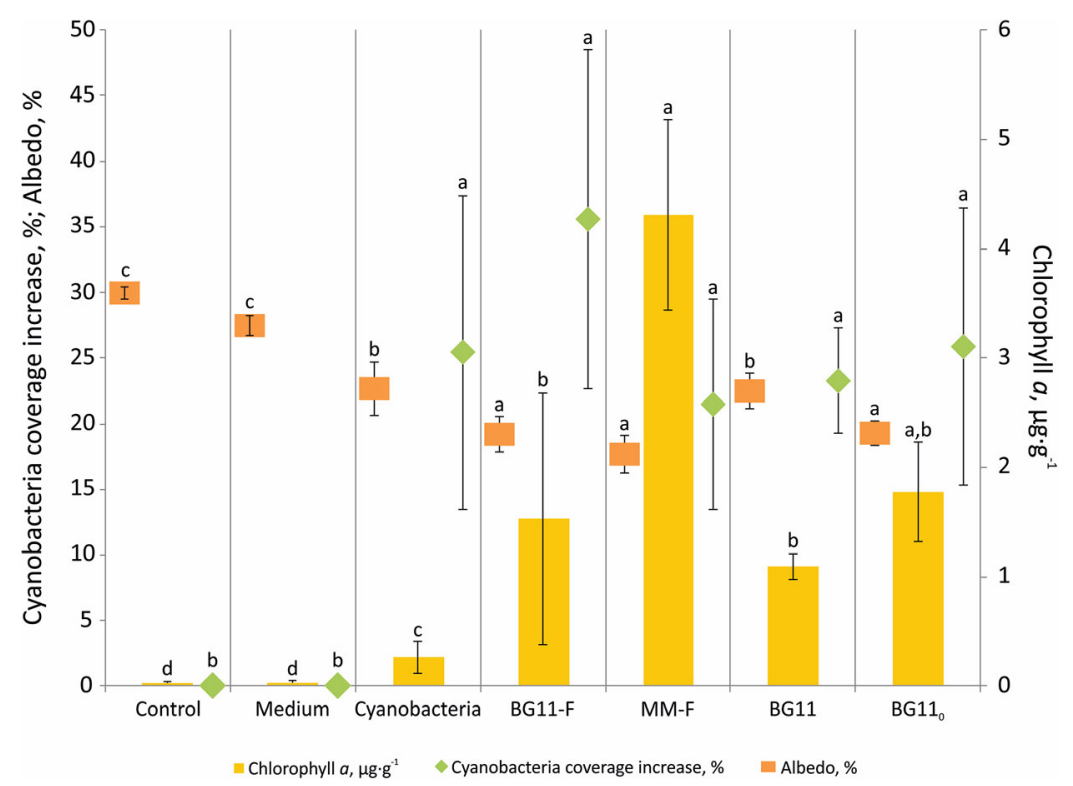

Fig. 2 Artificial biocrust characteristics after 3 months (chlorophyll $a$, albedo, final cyanobacteria coverage). All data are means ( $n=4)$. The error bars represent $\pm \mathrm{SE}$ and letters indicate significant differences $(p<0.05)$ among treatments 
Fig. 3 Images of induced biocrust samples after 3 months for each treatment

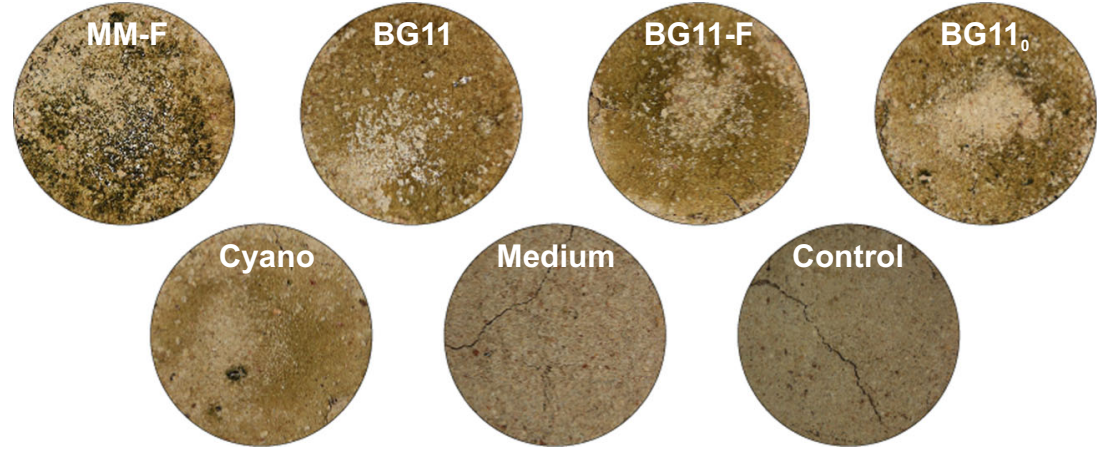

and Cyanobacteria (Fig. 5). Of the inoculants that performed best, the biomass cultured in MM-F medium (3 $\mathrm{mg} \mathrm{g}^{-1}$ ) produced significantly more TB-EPS and LB-EPS, followed by the BG11 $1_{0}$ medium $\left(1.2 \mathrm{mg} \mathrm{g}^{-1}\right)$.

\section{Optimized model}

The cyanobacteria cultured in the MM-F medium, which was one of the cheapest media, produced a sufficient amount of biomass. At the maximum biomass concentration reached in this medium $\left(3.1 \mathrm{~g} \mathrm{~L}^{-1}\right)$ and a cost of $0.003 € \mathrm{~L}^{-1}$, the amount of MM-F required to inoculate 1 ha at a concentration of $6 \mathrm{~g} \mathrm{~m}^{-2}$ would cost $66 €$, which is $295 € \mathrm{ha}^{-1}$ less than with BG11. Furthermore, as the cyanobacteria produced in MM-F also led to better biocrust properties, the growth model for large-scale production was developed for this culture media. The experimental parameters required to develop this growth model based on Molina Grima et al. (1993) were the extinction coefficient, the growth rate, and the average irradiance. The measured extinction coefficient, a specific property of the biomass, was $0.076 \mathrm{~m}^{2} \mathrm{~g}^{-1}$. From this, the average irradiance inside the batch culture was calculated and experimental growth rates were fitted to this variable (Fig. 6). The rest of the characteristic parameters were determined by non-linear regression. The maximum specific growth rate $\left(\mu_{\max }\right)$ found was 0.46 day $^{-1}$, close to the maximum reported for other cyanobacteria species (Markou and Georgakakis 2011), whereas the irradiance constant $\left(I_{\mathrm{k}}\right)$, meaning the irradiance necessary to reach

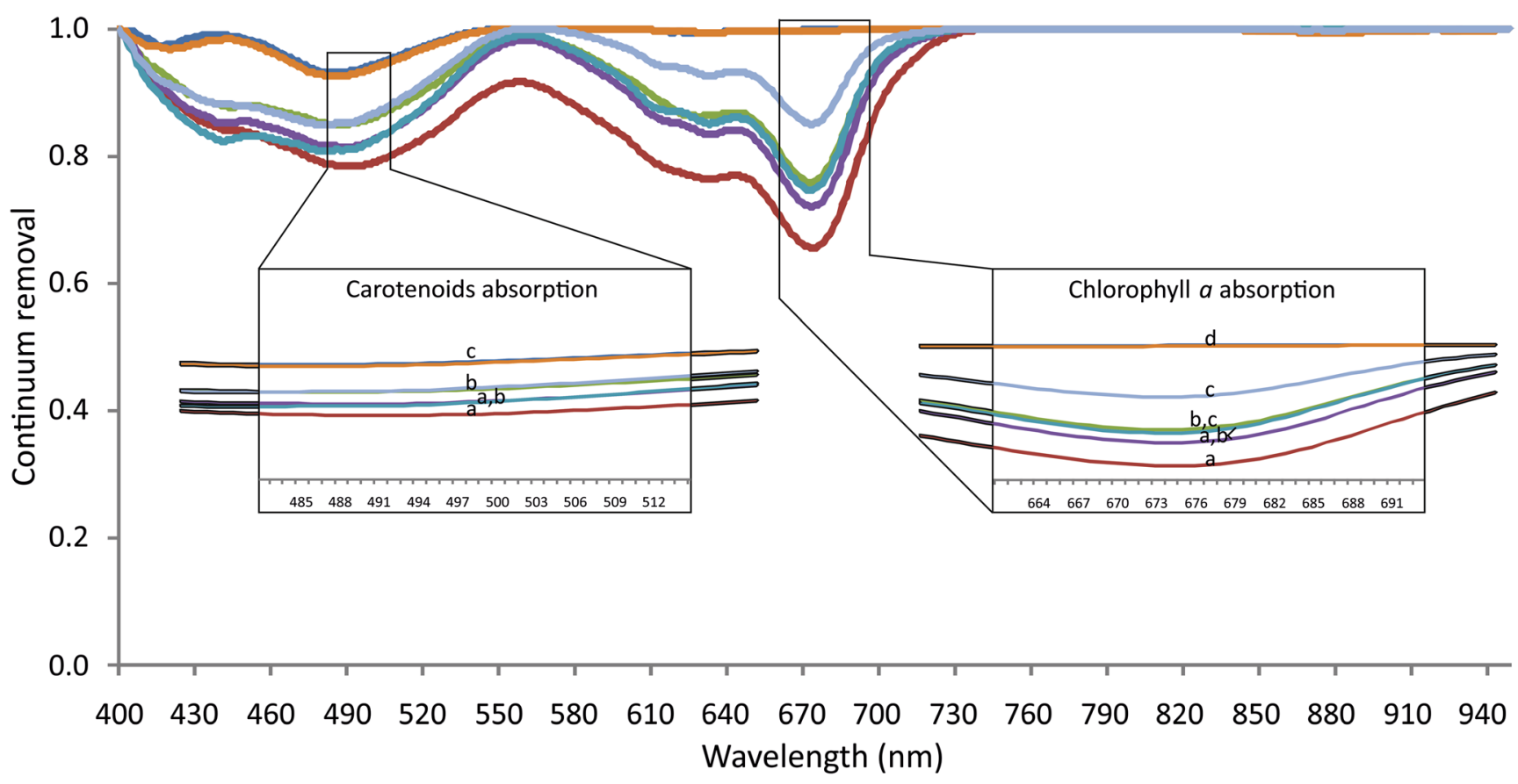

Control $=$ Medium Cyanobacteria $=$ BG11 ${ }_{0} \quad$ BG11 $=$ BG11-F

Fig. 4 Continuum removal of chlorophyll $a$ and carotenoid soil absorption of each treatment. All data are means $(n=4)$. Letters indicate significant differences $(p<0.05)$ among treatments 
Fig. 5 Changes in soil chemical properties induced by cyanobacteria inoculation (SOC and EPS content). All data are means $(n=4)$. The error bars represent $\pm \mathrm{SE}$ and letters indicate significant differences $(p<0.05)$ among treatments

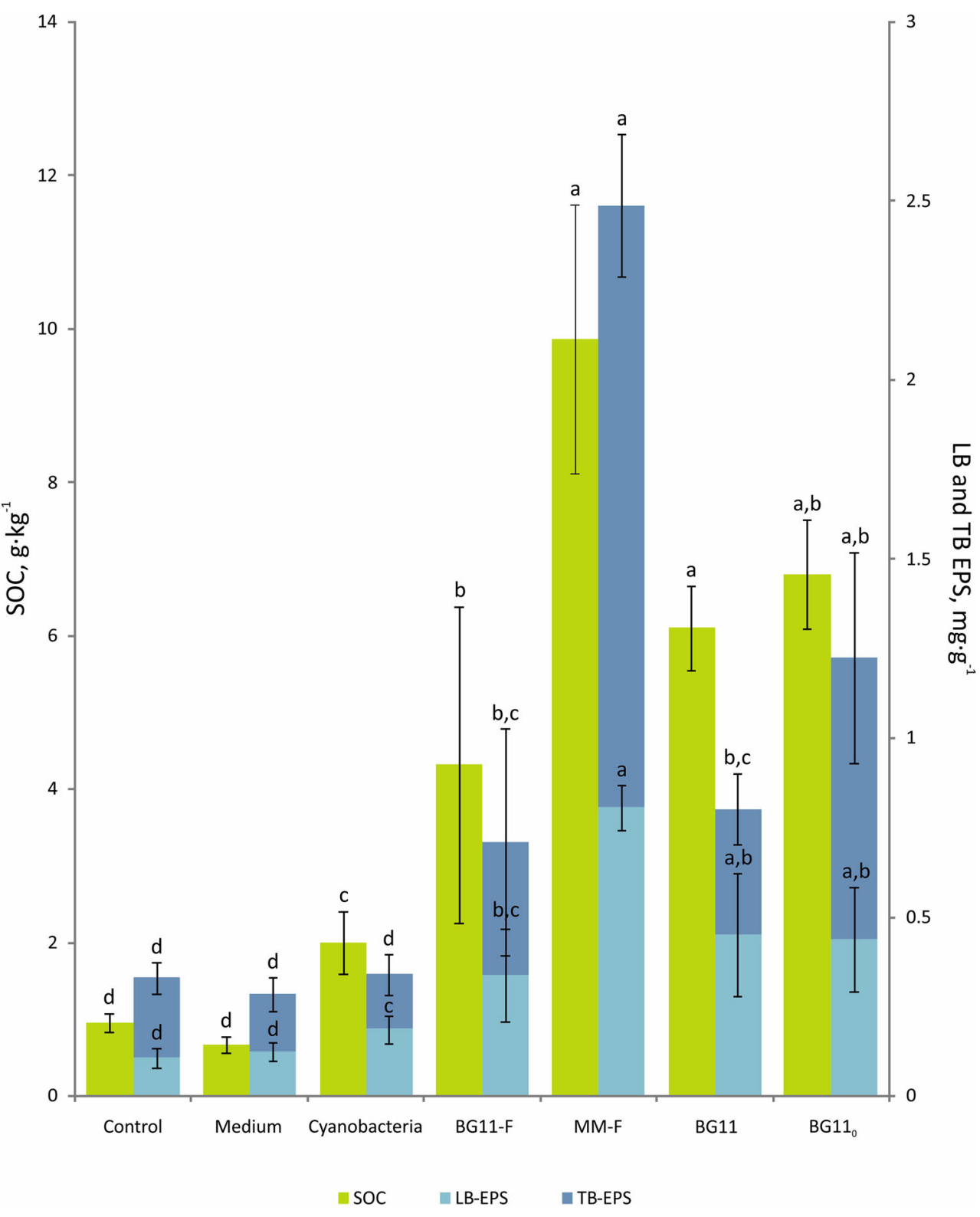

half of the maximum specific growth rate, was $120 \mu \mathrm{mol}$ photons $\mathrm{m}^{-2} \mathrm{~s}^{-1}$, with a form parameter $(n)$ equal to 3. After the growth model had been found, a wide range of average irradiances was introduced to calculate their respective model growth rates, shown as a hyperbole in Fig. 6.

\section{Discussion}

The effects of Nostoc cyanobacteria on soil properties have been studied previously (Falchini et al. 1996; McKenna Neuman et al. 1996; Maqubela et al. 2010; Román et al. 2018), but the influence of culture growing conditions on the final performance of the soil and optimal growing conditions for the best overall process efficiency and cost has received very little attention. Production has to be optimized to large-scale application of the process. Thus, low-cost culture media must be selected and suitable growth models for scaling up production developed. This study tested two conventional media employed for cyanobacterial production made with chemicals, BG11 and BG11 , which are, respectively, 0.027 and $0.015 € \mathrm{~L}^{-1}$ more expensive than the two fertilizer media tested, BG11-F and MM-F.

\section{Biomass production}

We studied the growth of $N$. commune in four different media prepared using chemicals or fertilizers and with or without a 


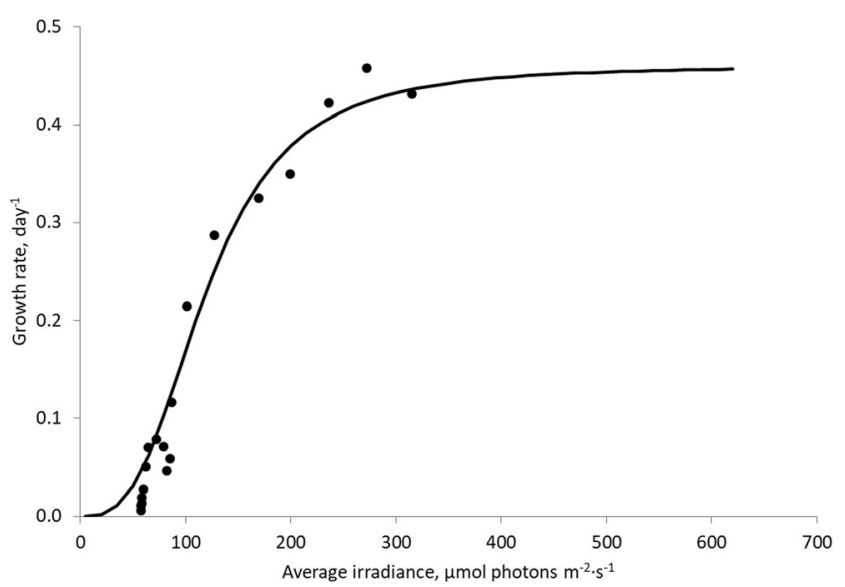

Fig. 6 Variation in Nostoc commune growth rate in the MM-F medium as a function of the average irradiance the cells are exposed to inside the culture. The continuous line represents the fit of the hyperbolic growth model to the experimental results (dots). All data are means $(n=3)$

nitrogen source. The largest biomass concentration was found in the BG11 chemical medium with nitrogen (BG11), whereas the minimum was also in the BG11 medium using chemicals $\left(\mathrm{BG} 11_{0}\right)$ but with no nitrogen source. The BG11-F biomass concentration at the end of the batch culture was close to BG11 (Fig. 1a), showing that the fertilizers might not provide as many nutrients as the culture medium prepared with chemicals. Nevertheless, biomass concentrations were sufficient to produce the required soil inoculants. It is also one of the cheapest media $\left(0.003 € \mathrm{~L}^{-1}\right)$, and therefore can be considered a feasible option. With the Mann and Myers medium (MM-F), with fertilizers and nitrogen, the biomass concentration was only slightly higher than without nitrogen, suggesting that some nutrient in this medium was limiting the growth of $N$. commune. This could be of interest for future investigation. The biomass concentration with the culture in the nitrogen-free medium $\left(\mathrm{BG} 11_{0}\right)$ may have been the lowest because the cells require more energy for $\mathrm{N}_{2}$ fixation than for nitrate (Lara and Guerrero 1997). As the chlorophyll fluorescence measurements $\left(F_{\mathrm{v}} / F_{\mathrm{m}}\right)$ ranged from 0.35 to 0.45 in all cases, which is lower than the 0.6-0.7 expected for green algae, but similar to other measurements in cyanobacteria of 0.4 (Wu et al. 2013a, b), our cultures were not stressed. According to Schuurmans et al. (2015), $F_{\mathrm{v}} / F_{\mathrm{m}}$ in cyanobacteria may be underestimated due to intertwining with the respiratory pathway, which leads to a higher $F_{0}$ (minimal fluorescence) after dark incubation, because the PSII primary quinone $\left(Q_{\mathrm{A}}\right)$ cannot be fully oxidized. In addition, the culture medium not only limits the biomass concentration but also the growth rate, biomass productivity, and biochemical composition of the biomass, in this case, the production of exopolysaccharides suitable for biocrust formation. According to Whitton and Potts (2012) the different forms in which nutrients are present in the environment can affect the physiological characteristics of cyanobacteria and their capacity to survive.

The negative effect of nutrient limitation on the performance of cyanobacteria has previously been reported
(Goldman 1979). The average growth rate of cyanobacteria calculated by Lürling et al. (2013) based on growth data from 16 genera (including one from Nostoc) is $0.65 \mathrm{day}^{-1}$. In this study, the maximum growth rate found with culture media containing a nitrogen source (Fig. 1b) was close to that average. However, biomass productivity is more relevant, because it is a better measure of process capacity. Biomass productivity is a function of strain capacity and suitability of culture conditions for the selected strain. Thus, several parameters, such as temperature, $\mathrm{pH}, \mathrm{CO}_{2}$ supply, dissolved oxygen concentration, cyanobacteria physiological state, or nutrient supply, can determine biomass productivity. However, if all of them are optimal, light availability is the determining factor (Molina Grima et al. 1993). The maximal biomass productivity was obtained with the BG11 medium containing a nitrogen source and either chemicals or fertilizers (Fig. 1c). Theoretically, the maximum productivity is achieved when the growth rate is half of the maximum growth rate (Fernández et al. 1998; Gomez-Serrano et al. 2015). Thus, because the experimentally measured maximal growth rate was 0.5 day $^{-1}$, the expected optimal growth rate would be 0.25 day $^{-1}$, close to the experimental rate. The Mann and Myers medium showed a maximum biomass productivity close to the BG11 medium (Fig. 1c). Finally, the lowest biomass productivity was measured in the BG11 nitrogen-free medium, thus confirming that this culture medium is unsuitable for large-scale production.

\section{EPS production in liquid culture}

The exopolysaccharides (EPS) produced by cyanobacteria in liquid culture can be divided into two main groups: REPS (Released EPS), which are excreted into the liquid culture when they become detached from the cells and those that remained covalently linked to the cell surface (CEPS), as sheaths or capsules (Pereira et al. 2009). As in this study, $N$. commune did not produce different amounts of REPS after 
being cultured in different media, the significant differences found in the total EPS quantities were caused by a difference in CEPS production (Fig. 1d). The lowest total EPS concentration in this study was in the nitrogen-free BG11 media (Fig. 1d), which may be because hypothetically, in absence of a combined nitrogen source, cells must invest more energy to fix $\mathrm{N}_{2}$, and hence have less energy available for EPS production (Pereira et al. 2009). However, this process seems to be species-specific and different factors are probably involved, because contradictory patterns have been described by other authors who have reported an increase in EPS production under nitrogen starvation conditions (De Philippis and Vincenzini 1998; Kumar et al. 2007). The total EPS concentration was the highest with the BG11 medium with a nitrogen source and chemicals (Fig. 1d). With fertilizers, the total amount of EPS produced was lower even though the culture medium contained the same concentration of nitrogen. This could be due to the difference in the composition of the nitrogen sources used in them (De Philippis and Vincenzini 1998), as $\mathrm{Ca}\left(\mathrm{NO}_{3}\right)_{2}$ was added to fertilizers and $\mathrm{NaNO}_{3}$ to chemicals (Table 1). Also, the higher concentration of calcium in the MM-F medium may have influenced strain performance or precipitation of other components, which would then not be available to cyanobacteria. The differences in total EPS quantities measured could also be due to factors involved in the induction of the metabolic processes during the EPS production.

\section{Characteristics of the biocrust induced by inoculation}

As cyanobacteria colonize the soil surface (Fig. 3), it becomes darker, decreasing albedo, as shown by Román et al. (2018). The results reported here show how all inoculants containing cyanobacteria led to lower soil albedo than the control or the Medium inoculants (Fig. 2). The albedo produced by cyanobacteria cultured in the MM-F, BG11-F, and BG11 0 media was significantly lower (Fig. 2).

Cyanobacteria coverage of soil surfaces significantly increased after inoculating $N$. commune in all culture media (Figs. 2 and 3). Again, the biomass cultured in MM-F medium led to significantly higher chlorophyll $a$ content than any other treatment except for BG11 $1_{0}$. An increase in chlorophyll $a$ with natural biocrust development has been reported (Castle et al. 2011), suggesting that it is an indicator of soil colonization by cyanobacteria. As the soils were sterilized and all the inoculants provided the same quantity of $N$. commune to the inoculated soils, the differences in chlorophyll $a$ content after 3 months are probably correlated with the soil colonizing capacity of each inoculum.

The soils with the MM-F inoculum had the highest chlorophyll $a$ content and absorption, carotenoid absorption and lowest albedo, indicating that cyanobacteria cultured in this medium had a higher soil colonization capacity than the rest of the inoculants. Furthermore, as observed in Fig. 2, results with the Medium inoculum, which were not significantly different from the control, did not show any improved soil characteristics. Although inoculation of $N$. commune in distilled water did not generally perform as well as the BG11-F treatment, it was still significantly better than the Medium inoculum. Thus, there must be a synergistic effect when inoculating $N$. commune with traces of culture media, which does not contribute to changes in soil properties, but helps cyanobacteria to survive and colonize the soil. This input of micro and macronutrients could be overcoming the lack of key nutrients in the quarry substrate, especially in the first stages, leading to a positive effect on cyanobacteria colonization, as previous data have shown for mosses and lichens, which are other BSC components (Bowker 2007).

\section{Changes in soil chemical properties}

The inoculation of $N$. commune led to a significant increase in SOC content in all cases, showing the best performance when it was cultured in the MM-F medium (Fig. 5). Cyanobacteria fix carbon and transform it into compounds that are released into the soil, increasing the SOC content (Chamizo et al. 2012; Lange and Belnap 2016). Previous cyanobacteria inoculation tests employing strains of the Nostoc genus have also reported an increase in SOC (Rogers and Burns 1994; Muñoz-Rojas et al. 2018; Román et al. 2018). The $N$. commune strain has already been tested as an inoculum on unsterilized limestone quarry soils, characterized as a very poor substrate with $1.12 \mathrm{~g} \mathrm{~kg}^{-1}$ of SOC content (Luna et al. 2016), where total organic carbon gains were over 1000\% (Román et al. 2018).

Both TB-EPS and LB-EPS significantly increased on soil when cyanobacteria were inoculated, especially in the MM-F medium (Fig. 5), even though it was not the treatment with the highest EPS concentration in the culture media (Fig. 1d). According to Mager and Thomas (2011), EPS composition is different depending on whether the cyanobacteria are under nutrient limitations, such as in dryland soils, or in a nutrientrich culture media. Our results suggest that apart from composition, EPS production also depends on whether cyanobacteria are in a liquid or soil environment. Moreover, the culture media employed to produce the cyanobacteria biomass also affected EPS content both in the liquid media (Fig. 1d) and when used to induce soil biocrust (Fig. 5). One cause could be that the differences in media influence the cyanobacterial physiological state, affecting their capacity to adapt to the soil environment and produce EPS. Furthermore, we did not find any relationship between a higher concentration of EPS in liquid culture and the performance of $N$. commune after being inoculated on soil. For example, the BG11 had the highest total EPS content at the end of the batch culture, but the lowest chlorophyll $a$ content of the soils inoculated with cyanobacteria and traces of media (Fig. 2). This suggests that EPS from liquid culture did not play a key role in 
the soil colonization process or further soil improvement, which only increased by inoculating cyanobacteria with their own media.

\section{Optimized model}

Analysis of the biocrust properties shows how the $N$. commune inoculum produced with MM-F as the culture medium had a stronger effect on soil improvement. As the growth performance with this medium was optimum, it is highly recommended for such applications, especially because it is prepared using fertilizers instead of pure chemicals, which reduces the cost of the culture media production by $295 € \mathrm{ha}^{-1}$. The process growth model for large-scale $N$. commune production must be developed at the experimental conditions used, as this is the first step in defining a large-scale bioreactor design and operating mode. The results for a growth model based on Molina Grima et al. (1993) confirm hyperbolic variation in growth rate with the average irradiance the cells are exposed to inside the culture. The maximum specific growth rate $\left(\mu_{\max }\right)$ found was close to the maximum reported for other cyanobacteria species (Markou and Georgakakis 2011). Using this parameter, the irradiance constant $\left(I_{\mathrm{k}}\right)$ and the form parameter $(n)$, the growth model fit the experimental results (Fig. 6). It is therefore a valuable tool for designing large-scale production of this strain for dryland soil restoration strategies.

\section{Conclusions}

This study showed that Nostoc commune can be cultured in media made with fertilizers, thus reducing media production costs by up to $295 € \mathrm{ha}^{-1}$. Furthermore, the inoculation of biomass cultured in the MM-F medium promoted significant improvements in soil properties under laboratory conditions. BG11-F medium alone did not promote changes in the soil, while inoculating $N$. commune with the same medium showed a synergistic effect on its colonization and soil properties. This suggests that inoculation with media would assist cyanobacteria colonization. In order to apply this method, which could assist other types of restoration, further studies should be done to confirm these results on soils with different characteristics. Finally, a growth model is provided for the optimization of future large-scale production of this strain for arid soil restoration.

Acknowledgements This work was supported by the Spanish National Plan for Research, Development and Innovation, including European Union of Regional Development Funds, under the RESUCI (CGL201459946-R) research project; the foundation Tatiana Pérez de Guzmán el Bueno, under its predoctoral fellowship program, the FPU predoctoral fellowship from the Educational, Culture and Sports Ministry of Spain (FPU14/05806) and project SABANA (grant \# 727874) from the
European Union's Horizon 2020 Research and Innovation program. We are most grateful to Estación Experimental Las Palmerillas from Cajamar, Holcim-España S.A. and Estación Experimental de Zonas Áridas (Spanish Council of Research, CSIC) for collaborating in this research.

Publisher's note Springer Nature remains neutral with regard to jurisdictional claims in published maps and institutional affiliations.

\section{References}

Acien FG, Fernandez JM, Magan JJ, Molina E (2012) Production cost of a real microalgae production plant and strategies to reduce it. Biotechnol Adv 30:1344-1353

Ahmed M, Moerdijk-Poortvliet TCW, Wijnholds A, Stal LJ, Hasnain S (2014) Isolation, characterization and localization of extracellular polymeric substances from the cyanobacterium Arthrospira platensis strain MMG-9. Eur J Phycol 49:143-150

Allen MB, Arnon DI (1955) Studies on nitrogen-fixing blue-green algae. I. Growth and nitrogen fixation by Anabaena cylindrica Lemm. Plant Physiol 30:366-372

Barceló-Villalobos M, Guzmán Sánchez JL, Martín Cara I, Sánchez Molina JA, Acién Fernández FG (2018) Analysis of mass transfer capacity in raceway reactors. Algal Res 35:91-97

Beer A (1852) Bestimmung der Absorption des rothen Lichts in farbigen Flüssigkeiten. Ann Phys 86:78-88

Belnap J (2003) Factors influencing nitrogen fixation and nitrogen release in biological soil crusts. In: Belnap J, Lange OL (eds) Biological soil crusts: structure, function, and management. Springer, Berlin, pp 241-261

Belnap J, Eldridge D (2003) Disturbance and recovery of biological soil crusts. In: Belnap J, Lange OL (eds) Biological soil crusts: structure, function, and management. Springer, Berlin, pp 363-383

Belnap J, Weber B, Büdel B (2016) Biological soil crusts as an organizing principle in drylands. In: Weber B, Büdel B, Belnap J (eds) Biological soil crusts: an organizing principle in drylands. Springer, Cham, pp 3-13

Bowker MA (2007) Biological soil crust rehabilitation in theory and practice: an underexploited opportunity. Restor Ecol 15:13-23

Box GEP, Cox DR (1964) An analysis of transformations. J Roy Stat Soc B 26:211-252

Cano-Díaz C, Mateo P, Muñoz-Martín MÁ, Maestre FT (2018) Diversity of biocrust-forming cyanobacteria in a semiarid gypsiferous site from Central Spain. J Arid Environ 151:83-89

Castle SC, Morrison CD, Barger NN (2011) Extraction of chlorophyll a from biological soil crusts: a comparison of solvents for spectrophotometric determination. Soil Biol Biochem 43:853-856

Chamizo S, Cantón Y, Miralles I, Domingo F (2012) Biological soil crust development affects physicochemical characteristics of soil surface in semiarid ecosystems. Soil Biol Biochem 49:96-105

Chamizo S, Cantón Y, Rodríguez-Caballero E, Domingo F (2016) Biocrusts positively affect the soil water balance in semiarid ecosystems. Ecohydrology 9:1208-1221

Chen L, Xie Z, Hu C, Li D, Wang G, Li Y (2006) Man-made desert algal crusts as affected by environmental factors in Inner Mongolia, China. J Arid Environ 67:521-527

Chamizo S, Mugnai G, Rossi F, Certini G, De Philippis R (2018) Cyanobacteria inoculation improves soil stability and fertility on different textured soils: Gaining insights for applicability in soil restoration. Front Env Sci 6:49

Chen L, Rossi F, Deng S, Liu Y, Wang G, Adessi A, De Philippis R (2014) Macromolecular and chemical features of the excreted extracellular polysaccharides in induced biological soil crusts of different ages. Soil Biol Biochem 78:1-9 
Clark RN, Roush TL (1984) Reflectance spectroscopy: quantitative analysis techniques for remote sensing applications. J Geophys Res 89: 6329-6340

Cosgrove J, Borowitzka MA (2010) Chlorophyll fluorescence terminology: an introduction. In: Suggett DJ, Prášil O, Borowitzka MA (eds) Chlorophyll $a$ fluorescence in aquatic sciences: methods and applications. Springer, Dordrecht, pp 1-17

De Philippis R, Vincenzini M (1998) Exocellular polysaccharides from cyanobacteria and their possible applications. FEMS Microbiol Rev 22:151-175

Dodds WK, Gudder DA, Mollenhauer D (1995) The ecology of Nostoc. J Phycol 31:2-18

Dubois M, Gilles KA, Hamilton JK, Rebers PA, Smith F (1956) Colorimetric method for determination of sugars and related substances. Anal Chem 28:350-356

Falchini L, Sparvoli E, Tomaselli L (1996) Effect of Nostoc (Cyanobacteria) inoculation on the structure and stability of clay soils. Biol Fert Soils 23:346-352

Fernández FGA, Camacho FG, Pérez JAS, Sevilla JMF, Grima EM (1998) Modeling of biomass productivity in tubular photobioreactors for microalgal cultures: effects of dilution rate, tube diameter, and solar irradiance. Biotechnol Bioeng 58:605-616

Fernandez I, Acien FG, Fernandez JM, Guzman JL, Magan JJ, Berenguel M (2012) Dynamic model of microalgal production in tubular photobioreactors. Bioresour Technol 126:172-181

Gao K, Ye C (2007) Phtosynthetic insensitivity of the terrestrial cyanobacterium Nostoc flagelliforme to solar UV radiation while rehydrated or desiccated. J Phycol 43:628-635

Garcia-Pichel F, Castenholz RW (1991) Characterization and biological implications of scytonemin, a cyanobacterial sheath pigment. J Phycol 27:395-409

Goldman JC (1979) Outdoor algal mass cultures-II. Photosynthetic yield limitations. Water Res 13:119-136

Gomez-Serrano C, Morales-Amaral MM, Acien FG, Escudero R, Fernandez-Sevilla JM, Molina-Grima E (2015) Utilization of secondary-treated wastewater for the production of freshwater microalgae. Appl Microbiol Biotechnol 99:6931-6944

Grima EM, Camacho FG, Pérez JA, Sevilla JM, Fernández FG, Gómez AC (1994) A mathematical model of microalgal growth in lightlimited chemostat culture. J Chem Technol Biotechnol 61:167-173

Guzmán-Murillo MA, López-Bolaños CC, Ledesma-Verdejo T, RoldanLibenson G, Cadena-Roa MA, Ascencio F (2007) Effects of fertilizer-based culture media on the production of exocellular polysaccharides and cellular superoxide dismutase by Phaeodactylum tricornutum (Bohlin). J Appl Phycol 19:33-41

Hu C, Gao K, Whitton BA (2012) Semi-arid regions and deserts. In: Whitton BA (ed) Ecology of cyanobacteria II: their diversity in space and time. Springer, Dordrecht, pp 345-369

Kumar AS, Mody K, Jha B (2007) Bacterial exopolysaccharides a perception. J Basic Microbiol 47:103-117

Lan S, Wu L, Zhang D, Hu C (2013) Assessing level of development and successional stages in biological soil crusts with biological indicators. Microb Ecol 66:394-403

Lange OL, Belnap J (2016) How biological soil crusts became recognized as a functional unit: a selective history. In: Weber B, Büdel B, Belnap J (eds) Biological soil crusts: an organizing principle in drylands. Springer, Cham, pp 15-33

Lara C, Guerrero MG (1997) Interactions between carbon and nitrogen metabolism. In: Rai AK (ed) Cyanobacterial nitrogen metabolism and environmental biotechnology. Springer-Verlag/Narosa Publishing House, New Delhi, pp 131-155

Luna L, Pastorelli R, Bastida F, Hernández T, García C, Miralles I, SoléBenet A (2016) The combination of quarry restoration strategies in semiarid climate induces different responses in biochemical and microbiological soil properties. Appl Soil Ecol 107:33-47
Lürling M, Eshetu F, Faassen EJ, Kosten S, Huszar VLM (2013) Comparison of cyanobacterial and green algal growth rates at different temperatures. Freshw Biol 58:552-559

Mager DM, Thomas AD (2011) Extracellular polysaccharides from cyanobacterial soil crusts: a review of their role in dryland soil processes. J Arid Environ 75:91-97

Mann JE, Myers J (1968) On pigments, growth, and photosynthesis of Phaeodactylum tricornutum. J Phycol 4:349-355

Maqubela MP, Mnkeni PNS, Muchaonyerwa P, D'Acqui LP, Pardo MT (2010) Effects of cyanobacteria strains selected for their bioconditioning and biofertilization potential on maize dry matter and soil nitrogen status in a South African soil. Soil Sci Plant Nutr $56: 552-559$

Markou G, Georgakakis D (2011) Cultivation of filamentous cyanobacteria (blue-green algae) in agro-industrial wastes and wastewaters: a review. Appl Energy 88:3389-3401

McKenna Neuman C, Maxwell CD, Boulton JW (1996) Wind transport of sand surfaces crusted with photoautotrophic microorganisms. Catena 27:229-247

Mingorance MD, Barahona E, Fernández-Gálvez J (2007) Guidelines for improving organic carbon recovery by the wet oxidation method. Chemosphere 68:409-413

Molina Grima E, Sánchez Pérez JA, Garcia Camacho F, Garcia Sánchez JL, López Alonso D (1993) n-3 PUFA productivity in chemostat cultures of microalgae. Appl Microbiol Biotechnol 38:599-605

Morales-Amaral MDM, Gómez-Serrano C, Acién FG, Fernández-Sevilla JM, Molina-Grima E (2015) Outdoor production of Scenedesmus sp. in thin-layer and raceway reactors using centrate from anaerobic digestion as the sole nutrient source. Algal Res 12:99-108

Mugnai G, Rossi F, Felde VJMNL, Colesie C, Büdel B, Peth S, Kaplan A, De Philippis R (2018a) Development of the polysaccharidic matrix in biocrusts induced by a cyanobacterium inoculated in sand microcosms. Biol Fert Soils 54:27-40

Mugnai G, Rossi F, Felde VJMNL, Colesie C, Büdel B, Peth S, Kaplan A, De Philippis R (2018b) The potential of the cyanobacterium Leptolyngbya ohadii as inoculum for stabilizing bare sandy substrates. Soil Biol Biochem 127:318-328

Muñoz-Rojas M, Román JR, Roncero-Ramos B, Erickson TE, Merritt D, Aguila-Carricondo P, Cantón Y (2018) Cyanobacteria inoculation enhances carbon sequestration in soil substrates used in dryland restoration. Sci Total Environ 636:1149-1154

Nayak M, Thirunavoukkarasu M, Mohanty RC (2016) Cultivation of freshwater microalga Scenedesmus sp. using a low-cost inorganic fertilizer for enhanced biomass and lipid yield. J Gen Appl Microbiol 62:7-13

Park CH, Li XR, Zhao Y, Jia RL, Hur JS (2017) Rapid development of cyanobacterial crust in the field for combating desertification. PLoS One 12:e179903

Pereira S, Zille A, Micheletti E, Moradas-Ferreira P, De Philippis R, Tamagnini P (2009) Complexity of cyanobacterial exopolysaccharides: composition, structures, inducing factors and putative genes involved in their biosynthesis and assembly. FEMS Microbiol Rev 33:917-941

R Core Team (2017) R: A language and environment for statistical computing. R Foundation for Statistical Computing, Vienna, Austria

Rao B, Liu Y, Lan S, Wu P, Wang W, Li D (2012) Effects of sand burial stress on the early developments of cyanobacterial crusts in the field. Eur J Soil Biol 48:48-55

Rippka R, Deruelles J, Waterbury JB (1979) Generic assignments, strain histories and properties of pure cultures of cyanobacteria. J Gen Microbiol 111:1-61

Rodríguez-Caballero E, Cantón Y, Chamizo S, Afana A, Solé-Benet A (2012) Effects of biological soil crusts on surface roughness and implications for runoff and erosion. Geomorphology 145-146:8189 
Rodríguez-Caballero E, Knerr T, Weber B (2015) Importance of biocrusts in dryland monitoring using spectral indices. Remote Sens Environ 17:32-39

Rodríguez-Caballero E, Castro A, Chamizo S, Quintas-Soriano C, García-Llorente M, Cantón Y, Weber B (2017) Ecosystem services provided by biocrusts: from ecosystem functions to social values. $\mathrm{J}$ Arid Environ 2017:1-9

Rogers SL, Burns RG (1994) Changes in aggregate stability, nutrient status, indigenous microbial populations, and seedling emergence, following inoculation of soil withNostoc muscorum. Biol Fert Soils 18:209-215

Román JR, Roncero-Ramos B, Chamizo S, Rodriguez-Caballero E, Cantón Y (2018) Restoring soil functions by means of cyanobacteria inoculation: importance of soil conditions and species selection. Land Degrad Dev 2018:1-10

Roncero-Ramos B, Muñoz-Martín MA, Chamizo S, Fernández-Valbuena L, Mendoza D, Perona E, Cantón Y, Mateo P (2019) Polyphasic evaluation of key cyanobacteria in biocrusts from the most arid region in Europe. PeerJ 7:e6169

Rossi F, De Philippis R (2015) Role of cyanobacterial exopolysaccharides in phototrophic biofilms and in complex microbial mats. Life 5:1218-1238

Rossi F, Li H, Liu Y, De Philippis R (2017) Cyanobacterial inoculation (cyanobacterisation): perspectives for the development of a standardized multifunctional technology for soil fertilization and desertification reversal. Earth-Sci Rev 171:28-43

Rossi F, Mugnai G, De Philippis R (2018) Complex role of the polymeric matrix in biological soil crusts. Plant Soil 429:19-34

Sánchez Mirón A, Contreras Gómez A, García Camacho F, Molina Grima E, Chisti Y (1999) Comparative evaluation of compact photobioreactors for large-scale monoculture of microalgae. J Biotech 70:249-270
Savitzky A, Golay MJE (1964) Smoothing and differentiation of data by simplified least squares procedures. Anal Chem 36:1627-1639

Schopf JW (2013) The fossil record of cyanobacteria. In: Whitton BA (ed) Ecology of cyanobacteria II: their diversity in space and time. Springer, Dordrecht, pp 15-36

Schuurmans RM, van Alphen P, Schuurmans JM, Matthijs HC, Hellingwerf KJ (2015) Comparison of the photosynthetic yield of cyanobacteria and green algae: different methods give different answers. PLoS One 10:e0139061

Wang W, Liu Y, Li D, Hu C, Rao B (2009) Feasibility of cyanobacterial inoculation for biological soil crusts formation in desert area. Soil Biol Biochem 41:926-929

Weber B, Bowker M, Zhang Y, Belnap J (2016) Natural recovery of biological soil crusts after disturbance. In: Weber B, Büdel B, Belnap J (eds) Biological soil crusts: an organizing principle in drylands. Springer, Cham, pp 479-498

Whitton BA, Potts M (2012) Introduction to the cyanobacteria. In: Whitton BA (ed) Ecology of cyanobacteria II: their diversity in space and time. Springer, Dordrecht, pp 1-13

Wu L, Lan S, Zhang D, Hu C (2013a) Functional reactivation of photosystem II in lichen soil crusts after long-term desiccation. Plant Soil 369:177-186

Wu Y, Rao B, Wu P, Liu Y, Li G, Li D (2013b) Development of artificially induced biological soil crusts in fields and their effects on top soil. Plant Soil 370:115-124

Wu L, Zhu Q, Yang L, Li B, Hu C, Lan S (2018) Nutrient transferring from wastewater to desert through artificial cultivation of desert cyanobacteria. Bioresour Technol 247:947-953

Zhao Y, Bowker MA, Zhang Y, Zaady E (2016) Enhanced recovery of biological soil crusts after disturbance. In: Weber B, Büdel B, Belnap J (eds) Biological soil crusts: an organizing principle in drylands. Springer, Cham, pp 499-523 